\title{
Anoxic ATP depletion in neonatal mice brainstem is prevented by creatine supplementation
}

\author{
B Wilken, J M Ramirez, I Probst, D W Richter, F Hanefeld
}

\begin{abstract}
Background-Sufficient ATP concentrations maintain physiological processes and protect tissue from hypoxic damage. With decreasing oxygen concentration, ATP synthesis relies increasingly on the presence of phosphocreatine.

Aim-The effect of exogenously applied creatine on phosphocreatine and ATP concentrations was studied under control and anoxic conditions.

Methods-Pregnant mice were fed orally with creatine monohydrate $(2 \mathrm{~g} / \mathrm{kg}$ body weight/day). Brainstem slices from these mice pups were compared with those from pups of non-creatine supplemented pregnant mice. Measurements were performed under normoxic and anoxic conditions. In addition, brainstem slices from non-creatine treated mice pups were incubated for 3 hours in control artificial cerebrospinal fluid (CSF) $(n=10)$ or in artificial CSF containing $200 \mu M$ creatine $(n=10)$. ATP and phosphocreatine contents were determined enzymatically in single brainstem slices.
\end{abstract}

Results-ATP concentrations were in the same range in all preparations. However, there was a significant increase of phosphocreatine in the brainstems from pups of creatine fed mice when compared with the brainstems of pups from non-creatine treated mice or in non-incubated brainstems of control animals. After $\mathbf{3 0}$ minutes anoxia, ATP as well as phosphocreatine concentrations remained significantly higher in creatine pretreated slices compared with controls.

Conclusion-The data indicate that exogenous application of creatine is effective in neuroprotection.

(Arch Dis Child Fetal Neonatal Ed 2000;82:F224-F227)

Keywords: ATP; creatine; phosphocreatine; neuroprotection

I, Universität

Göttingen

I Probst

Department of Organismal Biology and Anatomy,

University of Chicago, Chicago, Illinois 60637 , USA

J M Ramirez

Correspondence to: Professor F Hanefeld,

University of Göttingen,

Pediatric and Pediatric

Neurology, Robert-Koch-Str.

40, 37075 Göttingen,

Germany

Accepted 22 October 1999

supply of energy to stabilise ionic homeosta energy consuming biochemical reactions, and physiological processes. The primary energy source is ATP generated via oxidative phosphorylation of $\mathrm{NADH}$ within mitochondria, ${ }^{12}$ which requires a sufficient oxygen supply. Under hypoxic conditions, ATP is primarily supplemented by the phosphocreatine pool, before anaerobic glycolysis is activated, leading to increased production of lactate and $\mathrm{H}^{+} .{ }^{134}$
The hypoxia induced fall of intracellular ATP results in multiple dysfunctions of neurones - for example, failure in $\mathrm{Ca}^{2+}$ regulating mechanisms leading to an uncontrolled rise of intracellular $\mathrm{Ca}^{2+}$ and subsequent cell damage. ${ }^{4}$ This explains why survival time of immature rats under anoxic conditions is directly correlated with the preservation of brain energy stores for regulating ion homeostasis. $^{5}$

Previous investigations demonstrated that the exogenous application of creatine increases the latency of anoxic depolarisation of neurones, ${ }^{6}$ thus prolonging cellular survival and stabilising synaptic transmission within the central nervous system. ${ }^{78}$ Previously, we described the application of prophylactic supplementation of creatine and the effects on the synaptic activity of the central respiratory network under anoxic conditions. ${ }^{9}$ Here, we present the changes in phosphocreatine and ATP concentrations within the brainstem in more detail using the identical experimental design.

The hypothesis that exogenous supplementation of creatine stabilises ATP concentrations during anoxic conditions through raised phosphocreatine pools was analysed in an in vitro brainstem preparation of neonatal mice.

\section{Experimental setup}

ATP and phosphocreatine contents in brainstem slices obtained from neonatal animals (P2) ( $n=60)$ were determined enzymatically.

In a first experimental setup, pregnant mice were fed orally with creatine monohydrate ( $2 \mathrm{~g} / \mathrm{kg}$ body weight/day) (Sigma, Deisenhofen, Germany) throughout pregnancy (20 \pm 1 day). Brainstem slices $(600 \mu \mathrm{M}$ thick) from these mice pups $(n=10)$ were compared with those from pups born to non-creatine supplemented pregnant mice $(n=10)$. Thereafter, mice pups from controls $(n=10)$ as well as from creatine treated animals $(\mathrm{n}=10)$ were exposed to anoxia for 30 minutes.

In a second series of experiments, brainstem slices from non-creatine treated mice pups were incubated for three hours in control artificial cerebrospinal fluid $(\mathrm{CSF})(\mathrm{n}=10)$ or in artificial CSF containing $200 \mu \mathrm{M}$ creatine $(n=10)$.

\section{Preparation}

Technical details of the transverse brainstem slice preparations have been described previously. ${ }^{10}$ The brainstem was isolated in ice cold artificial CSF and secured in a vibratome with its rostral end directed upwards. Slices were sectioned serially until the rostral 
Table 1 ATP concentrations for controls and supplemented pups under normoxic and anoxic conditions

\begin{tabular}{|c|c|c|c|c|c|c|}
\hline & \multicolumn{2}{|l|}{ Controls } & \multicolumn{2}{|c|}{ Creatine fed mothers } & \multicolumn{2}{|c|}{ Difference } \\
\hline & Absolute & Relative & Absolute & Relative & Absolute & Relative \\
\hline Normoxic & $9.4(0.1)$ & & $9.7(0.4)$ & & +0.3 & $3 \%$ \\
\hline Anoxic & $5.1(0.2)$ & & $9.0(0.1)$ & & +3.9 & $56 \%$ \\
\hline Difference & -4.3 & $54 \%$ & -0.7 & $8 \%$ & & \\
\hline
\end{tabular}

Values are mean (SE).

Absolute values in $\mu \mathrm{mol} /$ wet weight.

boundary of the so called pre-Bötzinger complex became visible. This region is crucial for the generation of the respiratory rhythm. ${ }^{11}$ The transverse slice ( $600 \mu \mathrm{m}$ thickness) containing the pre-Bötzinger complex is recognisable by cytoarchitectonic landmarks, such as the appearance of the inferior olive and the hypoglossal nucleus, and the disappearance of the facial nucleus. The next slice containing the pre-Bötzinger complex was transferred into a recording chamber for electrophysiological measurements or was immediately homogenised for biochemical analysis.

The preparation was superfused by artificial $\mathrm{CSF}$ (flow rate $10 \mathrm{ml} / \mathrm{min}$ ) at $29^{\circ} \mathrm{C}$ and was continuously gassed with carbogen $\left(95 \% \mathrm{O}_{2}\right.$ and $\left.5 \% \mathrm{CO}_{2}\right)$. The artificial CSF contained $128 \mathrm{mM} \mathrm{NaCl}, 3 \mathrm{mM} \mathrm{KCl}, 1.5 \mathrm{mM} \mathrm{CaCl}_{2}$, $1 \mathrm{mM} \mathrm{MgSO}, 24 \mathrm{mM} \mathrm{NaHCO}, 0.5 \mathrm{mM}$ $\mathrm{NaH}_{2} \mathrm{PO}_{4}$, and $30 \mathrm{mM}$ D-glucose, and was equilibrated with carbogen at $27^{\circ} \mathrm{C}$ to $\mathrm{pH} 7.4$. Anoxia was induced by gassing the artificial CSF with $95 \% \mathrm{~N}_{2}$ and $5 \% \mathrm{CO}_{2}$ over a period of 30 minutes.

\section{Biochemical analysis}

The rationale of the biochemical analysis was to determine the ATP, ADP, phosphocreatine, and creatine contents of brainstem slices to obtain information about the creatine kinase regulated transfer of phosphate from phosphocreatine to ADP, which results in de novo production of ATP.

Immediately after withdrawal from the recording chamber all slices were homogenised by ultrasound in $250 \mu \mathrm{l} \%$ perchloric acid and centrifuged for 15 minutes at $15500 \mathrm{~g}$. The supernatant fluid was neutralised by the

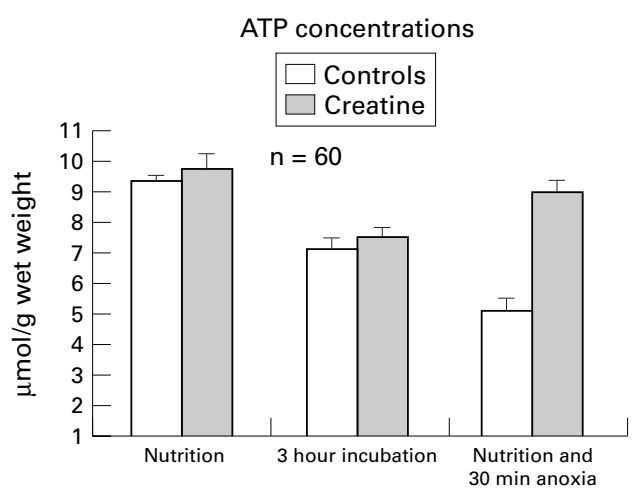

Figure 1 Anoxic changes of ATP concentrations in brainstem slices of neonatal animals. Slices were taken either from untreated animals ("controls") or were incubated for three hours in $200 \mu M$ creatine ("incubation") or alternatively taken from pups that were pretreated by feeding the pregnant mother animals with creatine ("nutrition") $(n=10$ each group $)$. Anoxia lasted for 30 minutes. addition of $\mathrm{KHCO}_{3}$ and recentrifuged. ATP and phosphocreatine was measured enzymatically by adding $30 \mu \mathrm{l}$ of a $100 \mathrm{mM}$ triethanolamin hydrochloride stem solution (containing $7 \mathrm{mM} \mathrm{MgCl}, 2 \mathrm{nmol}(4 \mu \mathrm{l}$ of $0.5 \mathrm{mM})$ NADP solution, $12 \mathrm{nmol}$ ADP $(4 \mu \mathrm{l}$ of $3 \mathrm{mM})$ solution, $8 \mathrm{nmol}$ glucose $(4 \mu \mathrm{l}$ of $2 \mathrm{mM})$, and $1 \mu \mathrm{l}$ G6P-DH) to $100 \mu \mathrm{l}$ of the homogenised brainstem slices. ${ }^{12}$ The enzymatic reaction was started with $0.5 \mu \mathrm{l}$ hexokinase. ATP was measured using a photometer with light absorption at $366 \mathrm{~nm}$. After the end of the biochemical reaction, $20 \mu \mathrm{l}$ creatine kinase was added to measure phosphocreatine contents. All ATP and phosphocreatine values are given in $\mu \mathrm{mol} / \mathrm{g}$ wet weight. Significant differences were determined by the Student's $t$ test.

\section{Results}

Using enzymatic tests, ATP values did not differ significantly between normal brainstem slices and those from mice pups of animals supplemented with creatine during pregnancy. Table 1 gives the ATP concentrations. There were also no significant changes in ATP concentrations when slices were incubated for three hours in artificial CSF or artificial CSF containing $200 \mu \mathrm{M}$ creatine: mean (SE) ATP concentrations were $7.2(0.2) \mu \mathrm{mol} / \mathrm{g}$ in control slices and $7.5(0.2) \mu \mathrm{mol} / \mathrm{g}$ in slices incubated in creatine supplemented artificial CSF. Both sets of values were significantly lower than in the group receiving oral supplementation via the mother animals.

After 30 minutes anoxia, there was a 54\% decrease in ATP values in neonatal control slices, whereas there was only an $8 \%$ decrease in ATP values in the creatine pretreated slices $(\mathrm{p}<0.05)$ (fig 1$)$.

The mean (SE) phosphocreatine concentration was $0.8(0.1) \mu \mathrm{mol} / \mathrm{g}$ in control slices and thus significantly different from the values found in slices obtained from pups of mother animals fed with creatine (mean, 1.9; SE, $0.1 \mu \mathrm{mol} / \mathrm{g}$; $\mathrm{p}<0.05)$. After three hours creatine incubation, the mean (SE) concentration of phosphocreatinine increased from $2.4(0.3) \mu \mathrm{mol} / \mathrm{g}$ to 3.2 $(0.4) \mu \mathrm{mol} / \mathrm{g}(\mathrm{p}<0.05$; fig 2$)$.

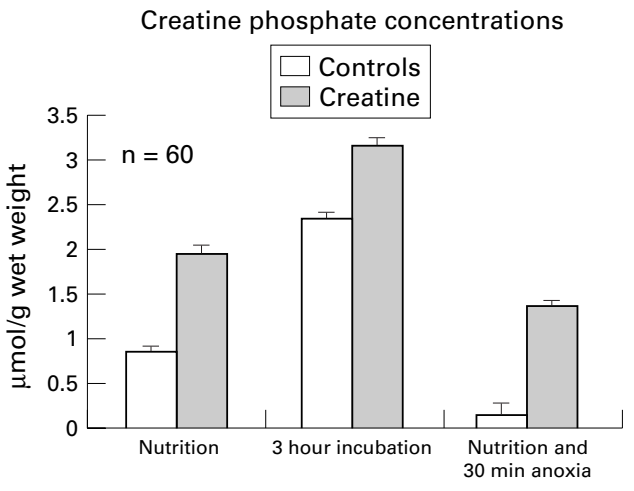

Figure 2 Anoxic changes of phosphocreatine concentrations in brainstem slices of neonatal animals. Slices were taken either from untreated animals ("controls") or were incubated for three hours in $200 \mu M$ creatine ("incubation"), or alternatively taken from pups that were pretreated by feeding the pregnant mother animals with creatine ("nutrition") $(n=10$ each group). Anoxia lasted for 30 minutes. 


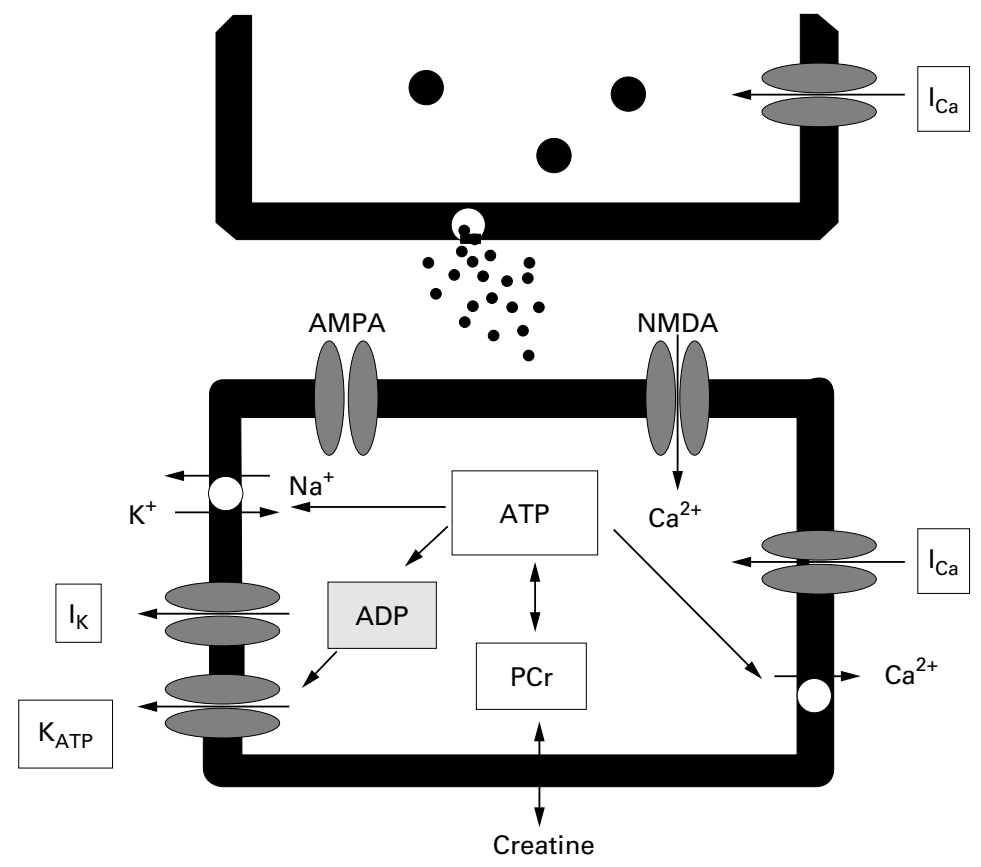

Figure 3 Schematic illustration of the most essential consequences of ATP stabilisation in neurones. ATP turnover is enhanced in all cases of hypoxic augmentation of neuronal activity. Increased ADP production leads to activation of $K^{+}$outward currents $\left(I_{K}\right)$ preferentially flowing through $A D P / A T P$ regulated $K_{\text {ATP }}$ channels, and the membrane potential of presynaptic and postsynaptic elements remains negative. ATPases regulate electrogenic $3 \mathrm{Na}^{+} / 2 \mathrm{~K}^{+}$pumping, they control active $\mathrm{Ca}^{2+}$ pumping into intracellular organelles, and indirectly ensure effective $\mathrm{Na}^{+}$coupled $\mathrm{Ca}^{2+}$ transportation across the plasma membrane. Such ATP dependent stabilisation of the membrane potential and cytosolic $\mathrm{Ca}^{2+}$ concentration also protects presynaptic $\mathrm{Ca}^{2+}$ inward currents that regulate release of the neurotransmitter glutamate. Unprotected hypoxic enhancement of specific and non-specific glutamate release would activate $\mathrm{Ca}^{2+}$ permeable NMDA-type ( $N$-methyl-D-aspartate) glutamate receptors, apart from the normally activated $\mathrm{Na}^{+}$permeable AMPA-type glutamate receptors. Such enhanced $\mathrm{Ca}^{2+}$ influx and depressed $\mathrm{Ca}^{2+}$ sequestration would lead to further membrane depolarisation and an excitotoxic rise in intracellular $\mathrm{Ca}^{2+}$ concentration. Thus, stabilisation of the ATP pool protects synaptic transmission between neurones even during severe hypoxia. AMPA, a-amino-3-hydroxy-5-methylinoxazolpropion-acid.

The most pronounced preservation of phosphocreatine values was seen in incubated slices. After 30 minutes anoxia, the mean (SE) phosphocreatine concentration was 1.4 $(0.1) \mu \mathrm{mol} / \mathrm{g}$ in creatine pretreated slices, whereas the phosphocreatine was almost completely depleted (mean, $0.1 ; \mathrm{SE}, 0.1 \mu \mathrm{mol} / \mathrm{g}$ ) in control slices $(p<0.05$; fig 2$)$.

\section{Discussion}

Using biochemical analysis, we found that oral treatment of pregnant mother animals with creatine or incubation of brainstem slices in creatine containing artificial CSF increased phosphocreatine concentrations and stabilised ATP values during anoxia in brain tissue of neonatal mice. ATP concentrations were lower, but not significantly different, in slices incubated for three hours either in normal or in creatine containing artificial CSF. However, phosphocreatine concentrations were significantly higher after slices were incubated in creatine containing artificial CSF or after they were incubated in artificial CSF without creatine. ATP concentrations were decreased in both groups after incubation for three hours. We interpret this finding to be the result of the low metabolic activity of slices held at a temperature of $27^{\circ} \mathrm{C}$.

After 30 minutes anoxia, ATP was significantly reduced $(54 \%)$ in control brainstem slices, while there was only a slight decrease of ATP values $(8 \%)$ in slices that were pretreated with creatine. In addition, phosphocreatine was only slightly decreased in creatine pretreated slices, whereas it was almost completely depleted after 30 minutes anoxia in control tissue.

Physiological processes and life rescuing mechanisms - for example, the highly energy demanding hypoxic augmentation of respiratory activity, ${ }^{9}$ depend on a sufficient energy supply and hence a sufficient phosphocreatine pool. Under normal conditions, phosphocreatine decreases rapidly to $40-50 \%$ during hypoxic conditions, which is accompanied by a comparable fall in ATP values, indicating failure of ATP synthesis. ${ }^{13} 14$ Such energy depletion is correlated with the onset of hypoxic depression of the central respiratory network, as Pierard and co-workers ${ }^{15}$ have shown by magnetic resonance spectroscopy. This neural response can easily be explained by the blockade of synaptic interaction within the network. ${ }^{15}$ Inhibitory synaptic transmission seems to be more sensitive to hypoxic stress, ${ }^{16}$ which leads to the danger of excitotoxicity of excitatory amino acids. Excessive excitation could lead to the massive influx of cations, which can lead to severe damage to neurones. This is particularly threatening to neonatal animals in which compensatory rescue mechanisms are underpowered. ${ }^{17}$ The immature isoform of the NMDA (N-methyl-D-aspartate) receptor reveals a higher open probability, and its deactivation is slower than that of adult NMDA receptors, resulting in an enhanced $\mathrm{Ca}^{2+}$ influx. ${ }^{17}$ This may be potentiated by a $\mathrm{Ca}^{2+}$ influx through depolarisation activated L-type $\mathrm{Ca}^{2+}$ channels. ${ }^{18}$ Immature brain tissue might not be able to cope with such a $\mathrm{Ca}^{2+}$ overload. The reason is that creatine kinase is three to six times less active in immature than in mature animals, which results in a limited energy pool. ${ }^{19}{ }^{20}$ The responsible cellular mechanisms for this observation are summarised in the scheme shown in fig 3.

In immature as well as in mature animals, cell death does not occur as long as the ATP content remains above $25 \%$ of control. ${ }^{21}$ This has important clinical implications, because stabilisation of a sufficient ATP content could be neuroprotective. ATP is needed for energy consuming processes such as $3 \mathrm{Na}^{+} / 2 \mathrm{~K}^{+}$and $\mathrm{Ca}^{2+}$ pumping, ${ }^{22}$ which are the key processes for ionic homeostasis determining neuronal excitability and synaptic transmission. Inhibitory and excitatory synaptic transmission should also be protected by increasing ATP supply. This is consistent with the finding that preincubation of neocortical cells with creatine also had a pronounced protective effect against hypoxic depression of synaptic transmission. ${ }^{7324}$

In conclusion, our data demonstrate that hypoxic energy failure in neonatal mice can be prevented by exogenous creatine applied before the hypoxic event. From this observation, the working hypothesis is derived that creatine might also be neuroprotective in humans. 
1 Vannucci RC. Experimental biology of cerebral hypoxicischemia: relation to perinatal brain damage. Pediatr Res 1990;27:317-26.

2 Erecinska $M$, Silver IA. ATP and brain function. $f$ Cereb Blood Flow Metab 1989;9:2-19.

3 Bessman SP. The creatine-creatine phosphate energy shuttle. Annu Rev Biochem 1985;54:831-62.

4 Lutz PL. Mechanisms for anoxic survival in the vertebrate brain. Annu Rev Physiol 1992;4:601-18.

5 Duffy TE, Kohle SJ, Vannucci RC. Carbohydrate and energy metabolism in perinatal rat brain: relation to survival in anoxia. $\mathcal{F}$ Neurochem $1974 ; 24: 271-6$.

6 Balestrino M. Pathophysiology of anoxic depolarization: new findings and a working hypothesis. $\mathcal{F}$ Neurosci Methods 1995;59:99-103

7 Whittingham TS, Lipton P. Cerebral synaptic transmission during anoxia is protected by creatine. $\mathcal{F}$ Neurochem during anoxia is

8 Lipton P, Whittingham TS. Reduced ATP concentration as a basis for synaptic transmission failure during hypoxia in the in-vitro guinea-pig hippocampus. f Physiol the in-vitro g

9 Wilken B, Ramirez JM, Probst I, Richter DW, Hanefeld F. Creatine protects the central respiratory system under anoxic conditions. Pediatr Res 1998;43:8-14.

10 Ramirez JM, Quellmalz UJA, Richter DW. Postnatal changes in the mammalian respiratory network as revealed by the transverse brainstem slice of mice. I Physio 1996;491:799-811.

11 Smith JC, Ellenberger HH, Ballanyi K, Richter DW, Feldman JL. Pre-Bötzinger complex: a brainstem region that may generate respiratory rhythm in mammals. Science 1991;254:726-9.

12 Lamprecht W, Stein P, Heinz F, Weisser H. Kreatinphosphat: Methoden der enzymatischen Anaylse. In: Bergmeyer HU, ed. Weinheim: Verlag Chemie. Band II Seite 1974:1825-9.

13 Tsuji M, Allred E, Jensen F, Holtzman D. Phosphocreatine and ATP regulation in the hypoxic developing rat brain. and ATP regulation in the hypo
Dev Brain Res 1995;85:192-200.
14 Jensen F, Tsuji M, Offutt M, Firkusny I, Holtzman D. Profound, reversible energy loss in the hypoxic immature brain. Brain Res Dev Brain Res 1993;73:99-105.

15 Pierard C, Champagnat J, Denavit-Saubie M, et al. Brain stem energy metabolism response to acute hypoxia in anaesthetized rats: a 31 P NMR study. NeuroReport 1995; 7:281-5.

16 Richter DW, Bischoff A, Anders K, Bellingham M, Windhorst $U$. Response of the medullary respiratory network of the cat to hypoxia. F Physiol 1991;443:231-56.

17 Johnston MV. Neurotransmitters and vulnerability of the developing brain. Brain Dev 1995;17:301-6.

18 Mironov SL, Richter DW. L-type $\mathrm{Ca}^{2+}$ channels in inspiratory neurons of mice and their modulation by hypoxia. f Physiol 1998;512:75-87.

19 Norwood WI, Ingall JS, Norwood CR, Fossel ET. Developmental changes of creatine kinase metabolism in rat brain. Am f Physiol 1983;244:C205-10.

20 Holtzman D, Tsuji M, Wallimann T, Hemmer W. Functional maturation of creatine kinase in rat brain. Dev Neurosci 1993;15:261-70.

21 Yager JY, Kala G, Hertz L, Juurlink BHJ. Correlation between content of high-energy phosphates and hypoxicischemic damage in immature and mature astrocytes. Brain Res Dev Brain Res 1994;82:62-8.

22 Rosenkrantz TS, Kubin J, Mishra OP, Smith D, DelivoriaPapadopoulos M. Brain cell membrane $\mathrm{Na}^{+}, \mathrm{K}^{+}$-ATPase activity following severe hypoxic injury in the newborn piglet. Brain Res 1996;730:52-7.

23 Luhmann HJ, Heinemann U. Hypoxia-induced functional alterations in adult rat neocortex. $\mathcal{f}$ Neurophysiol 1992;67:798-811.

24 Balestrino M, Rebaudo R, Lunardi G. Exogenous creatine delays anoxic depolarization and protects from hypoxic damage: dose-effect relationship. Brain Res 1999;816:12430 